\title{
Supported Au-Pt Catalysts \\ Characterization and Hydrogen Transfer Activity between \\ Benzene and Cyclohexane
}

\author{
S. Galvagno*† and G. Parravano $\ddagger$ \\ Department of Chemical Engineering, University of Michigan, Ann Arbor, Michigan 48100
}

Received April 21, 1978; revised September 21, 1978

Two series of Au-Pt catalysts supported on $\mathrm{SiO}_{2}$ were prepared by the incipient wetness method. In one series the total amount of metal $(\mathrm{Au}+\mathrm{Pt})$ was kept constant at about $0.7 \mathrm{wt} \%$ (Series A), while in a second series the amount of Pt was kept constant at about $0.7 \mathrm{wt} \%$ (Series B). In the latter the total amount of metal ranged between 1.03 to $6.13 \mathrm{wt} \%$. The two series were characterized by $\mathrm{H}_{2}$ and $\mathrm{O}_{2}$ chemisorption, wide-angle X-ray scattering, and electron spectroscopy for chemical analysis. There was indication of the presence of mixed $\mathrm{Au}-\mathrm{Pt}$ particles as well as of particles containing $\mathrm{Au}$ only. In depth compositional profile of Series B showed homogeneous composition extending to at least about $12 \AA$ below the surface, while in Series A compositional inhomogeneities were found. The rate of the carbon-14 equilibration between benzene and cychohexane and the rate of equilibration between $\mathrm{H}_{2}$ and $\mathrm{D}_{2}$ were measured on both catalyst series in a flow system at a total pressure of $1 \mathrm{~atm}$. For the carbon- 14 equilibration reaction the temperature was $205^{\circ} \mathrm{C}$, contact time in the range of 10 to $30 \mathrm{sec}$. The influence of the ratio cyclohexane to benzene on the reaction rate was recorded. For the deuterium equilibration the temperature was $-78^{\circ} \mathrm{C}$ and a ratio of $p_{\mathrm{D}_{2}} / p_{\mathrm{H}_{2}}=1$ was employed. The rate of the carbon-14 equilibration was found to be independent of surface composition of the Au-Pt particles for Series A, while for Series B the rate increased upon addition of $\mathrm{Au}$ to $\mathrm{Pt}$. Differences in rate up to about one order of magnitude were observed between catalysts from Series A and B possessing a similar overall $\mathrm{Au} / \mathrm{Pt}$ ratio. No difference in the rate of deuterium equilibration was found between Series $\mathrm{A}$ and Series B catalysts. The kinetic behavior of Series B is discussed, and suggestions of the nature of the $\mathrm{Au}-\mathrm{Pt}$ interaction, responsible for the enhancement of the reactivity of $\mathrm{Pt}$, are advanced. The concept of reaction sensitivity to surface structure is viewed as a dynamic factor which includes the position of the reaction steady state and the corresponding degree of reaction conversion. Consequently, a reaction may be sensitive or insensitive to the surface structure depending upon its eonversion.

The influence of several factors on the catalytic activity of $\mathrm{Au}$ was recently investigated (1). The factors studied included precursor salt, size and distribution of the Au particles, nature of the support matcrial, and gas phase oxidation-reduc-

* On leave from the Donegani Research Institute, Montedison S.p.A., Novara, Italy.

$\dagger$ To whom queries about this paper should be addressed.

$\ddagger$ Deceased on April 1, 1978. tion conditions. From these investigations a complex set of surface effects covering the structure and composition of the surface and the kinetics of the catalytic reaction were found. Against this background, it was felt of interest to investigate the effect of the addition to Au of a second metal with limited bulk solubility in Au. The condition of partial solubility seemed preferable to that of complete miscibility, since it appeared that in the presence of 
this condition it would be more likely to discover subtle interactions between the two metals that could be obscured by large three-dimensional alloy formation. In past studies on bimetallic systems, there has been an effort to strive for conditions leading to alloy formation, as predicted by the bulk phase diagram. This approach has been instrumental for the derivation of general schemes for the catalytic activity of supported alloys. It may also be argued that bimetallic compositions with large miscibility gap may, indeed, be important for throwing light on the genetic steps of bimetallic particles as they grow from the decomposition products of separate metal salts, on the possible existence and characterization of metal-metal interactions precursor to alloying, on the stabilization of genetic intermediates, on nonequilibrium particle morphology (anisotropic and two-dimensional growth). This is a vast area, whose microscopic details are largely unknown; yet it comprises steps which conceivably have a controlling role on the reactivity of bimetallic supported particles.

Following these considerations, it was felt that Pt would be a good candidate for the study of its effect on supported Au. In fact, the catalytic activity of $\mathrm{Pt}$ is generally orders of magnitude higher than that of $\mathrm{Au}$ and considerable research has already been carried out on supported (2-5) and unsupported (6-14) Au-Pt compositions. In the course of past research it was found that depending upon the procedure employed for the preparation of supported $\mathrm{Au}-\mathrm{Pt}$, alloying did or did not take place $(3,4)$.

The Au-Pt system displays a miscibility gap, within which a Pt-rich and an Aurich phase coexist (15). At $400^{\circ} \mathrm{C}$ the latter, extending up to about $18 \mathrm{wt} \% \mathrm{Pt}$, is a disordered substitutional solid solution. Under conditions of thermal equilibrium it is expected that Au will segregate at the surface, due to its lower sublimation energy. This has been confirmed in studies on $\mathrm{Au}-\mathrm{Pt}$ films by $\mathrm{H}_{2}$ chemisorption and work function measurements $(10,12)$. It was also found (11) as expected, that surface composition remained essentially constant as the bulk composition was modified within the range of the miscibility gap. Adsorption-desorption of $\mathrm{II}_{2}$ and $\mathrm{CO}$ has been employed to derive a more detailed picture of the film surface $(9,10)$. From these studies it was concluded that $\mathrm{Au}$ acted as a diluent for Pt, which formed atomic "ensembles" of different sizes. Au additions simply influenced the number of the smaller $\mathrm{Pt}$ "ensembles," causing variations in the relative intensity of the desorption peaks. In supported $\mathrm{Au}-\mathrm{Pt}$ (particle size 500$2000 \AA$ ) these conclusions seemed to be confirmed $(4,5)$, but questions on the possible influence of the size of the smaller particles, of the preparative conditions, and of the catalytic reaction itself remained unresolved. Indeed, with very small particles $(\widetilde{<} 25 \AA)$ the surface composition may become controlled by surface tension effects, or if thermal equilibration is not achieved, particle nucleation and growth effects may be determinant. If nucleation rates are appreciably different between the two metals one type of metal particle will be formed initially to be subsequently covered, partially or totally, by the other metal, irrespective of thermodynamic predictions. Nucleation and growth of the two metal particles may also be dependent upon the type of support employed and its pretreatment prior to contact with metal precursor salts. If under pretreatment of the catalyst and during reaction rate measurements no appreciable sintering or thermal equilibration takes place, surface composition is essentially fixed by preparative manipulations. The reaction employed to test the activity of the catalytic surface reflects the geometrical and electronic requirements of controlling adsorption-desorption steps, 
and surface models thus developed are dependent upon reaction kinetic characteristics. It becomes necessary to test these models with investigations on several reactions, possessing alternate requirements.

In view of these considerations it was deemed interesting to submit the supported $\mathrm{Au}-\mathrm{Pt}$ system to further scrutiny in view of seeking answers to the following questions: If alloys are not formed, as indicated by standard characterization methods, does the catalytic activity vary with overall composition in a way that it may be expected from a noninteracting particle of different catalytic activity? Within the phenomena controlling the physicochemical behavior of small metal particles on a ceramic support, is alloy formation the catalytically important interaction or are there more subtle ones which escape detection by the standard techniques employed for the definition of alloy formation? This question seems especially relevant, since in the range of small supported particles every physical technique employed for particle characterization yields results biased by the effect underlying the technique employed. Is the nature of the catalytic step an important consideration for the observation of interactions between the two metals outside the range of alloy formation?

These questions prompted us to investigate the catalytic activity of supported $\mathrm{Au}-\mathrm{Pt}$ preparations in hydrogen and oxygen transfer reactions. This communication summarizes the results obtained in the preparation and characterization of supported $\mathrm{Au}-\mathrm{Pt}$ samples and in their catalytic activity for hydrogen transfer reactions, while in a subsequent communication we shall present the results on oxygen transfer reactions. Because of the interest in employing well-defined and constant gas phase redox reaction conditions, isotopic exchange reactions have been used throughout.
EXPERIMENTAL

\section{Materials}

Reagent grade $\Lambda \mathrm{u}$ and l't chlorides, $\mathrm{SiO}_{2}$ (Davison Grade 62, surface area $340 \mathrm{~m}^{2} / \mathrm{g}$ ), high purity $(99.99 \%) \quad \mathrm{H}_{2}$ and $\mathrm{He}$ were employed. $\mathrm{H}_{2}$ was used after purification by passage through $\mathrm{Pd}$ asbestos at $400^{\circ} \mathrm{C}$, followed by a molecular sieve trap, kept at liquid $\mathrm{N}_{2}$ temperature, while $\mathrm{He}$ was passed through $\mathrm{Cu}$ turnings, $400^{\circ} \mathrm{C}$, followed by a charcoal trap cooled at liquid $\mathrm{N}_{2}$ temperature. Reagent grade benzene (BE) and cyclohexane, CHA, 14C-BE ( ${ }^{*} \mathrm{BE}$ ), $0.5 \mathrm{mCi}$ (radioactive purity $99.3 \%$ ) were employed without further purification. ${ }^{*} \mathrm{BE}$ was diluted with $\mathrm{BE}$ to about $0.1 \mathrm{mCi}$ as needed. Supported $\mathrm{Au}-\mathrm{Pt}$ catalysts were prepared by impregnation of the support with a solution of $\mathrm{H}_{2} \mathrm{PtCl}_{6}$ and $\mathrm{HAuCl}_{4}$ of the desired concentration. The amount of the impregnated solution was slightly greater than the pore volume of the silica gel $\left(1.15 \mathrm{~cm}^{3} / \mathrm{g}\right)$. After impregnation the catalysts were dried at $120^{\circ} \mathrm{C}$ for about $24 \mathrm{hr}$.

Two series of catalysts with various $\mathrm{Au} / \mathrm{Pt}$ ratios were prepared. In one series the total amount of metal was kept constant at about $0.7 \mathrm{wt} \%$ (Series A), while in a second series the amount of $\mathrm{Pt}$ was kept constant at about $0.7 \mathrm{wt} \%$ (Series B). In the latter the total amount of metal ranged between 1.03 and $6.13 \mathrm{wt} \%$. Two sets of $\mathrm{SiO}_{2}$-supported catalysts containing $\mathrm{Au}$ or $\mathrm{Pt}$ only were also prepared. $\Lambda$ summary of the pretreatments before adsorption and reaction rate measurements is presented in Table 1. Preparation and pretreatment of the Pt- or Au-supported catalysts were identical to those employed for the $\mathrm{Au}-\mathrm{Pt}$ series. Catalyst composition was determined by atomic absorption and neutron activation analysis. In the latter analysis separation of the neutron irradiated components in the $\mathrm{Au}-\mathrm{Pt}$ series was carried out by dissolution in $\mathrm{HNO}_{3}$; radiation counting was performed sepa- 
TABLE 1

Preparation and Pretreatment Conditions of Supported Au-Pt Catalysts

\begin{tabular}{|c|c|c|c|c|}
\hline \multirow{2}{*}{$\begin{array}{l}\text { Total metal } \\
(\mathrm{wt} \%)\end{array}$} & \multirow{2}{*}{$\stackrel{\mathrm{Au}}{(\operatorname{atom} \%)}$} & \multicolumn{3}{|c|}{ Treatment } \\
\hline & & $\mathrm{H}_{2}$ adsorption & $\mathrm{O}_{2}$ adsorption & Reaction \\
\hline \multicolumn{5}{|l|}{ Series A } \\
\hline 0.55 & 100 & Heated in air, 70 Torr, & After measurement of & $(\mathrm{BE}+\mathrm{CHA})$ \\
\hline 0.59 & 70 & $300^{\circ} \mathrm{C} 1 \mathrm{hr}$; heated & $\mathrm{H}_{2}$ adsorption, heated & Heated in $\mathrm{H}_{2}, 400^{\circ} \mathrm{C}$, \\
\hline 0.53 & 52 & in $\mathrm{H}_{2}, 70$ Torr, $400^{\circ} \mathrm{C}$, & in vacuum, $450^{\circ} \mathrm{C}$ & $2 \mathrm{hr}$; in $\mathrm{He}, 1 \mathrm{hr}$ \\
\hline 0.83 & 23 & $1 \mathrm{hr}$; evacuated & $30 \mathrm{~min}$, cooled to & cooled to reaction tem- \\
\hline 0.51 & 0 & $\begin{array}{l}450^{\circ} \mathrm{C}, 30 \mathrm{~min}, \text { cooled } \\
\text { to room temperature }\end{array}$ & $200^{\circ} \mathrm{C}$ & perature \\
\hline Series B & & & & $\left(\mathrm{H}_{2}+\mathrm{D}_{2}\right)$ \\
\hline 6.13 & 89 & & & Heated in $\mathrm{H}_{2}, 400^{\circ} \mathrm{C}$, \\
\hline 2.31 & 68 & & & $2 \mathrm{hr}$; cooled to reac- \\
\hline 1.40 & 45 & & & tion temperature \\
\hline 1.03 & 28 & & & \\
\hline
\end{tabular}

rately on the $\mathrm{Au}$ and $\mathrm{Pt}$ fractions. It was found that the results of both methods of analysis differed by less than $\pm 2.4 \mathrm{wt} \%$.

Catalyst characterization included $\mathrm{H}_{2}$ and $\mathrm{O}_{2}$ adsorption, wide-angle $\mathrm{X}$-ray scattering (WAXS) and electron spectroscopy for chemical analysis (ESCA). Adsorption measurements were carried out in a conventional glass vacuum system employing a thermocouple vacuum gauge. The experimental details of the adsorption apparatus have already been reported (16). WAXS spectra were obtained by means of an X-ray diffractometer with a resolution of $0.005^{\circ}$; rrystallite size was calculated with the aid of the Scherrer expression, after correction for the instrument contribution (17). CuKo wavelength was used. The ESCA patterns were recorded with a Physical Electronic Industries Spectrometer in which unmonochromatized $\mathrm{Mg} K \alpha$ line was the exciting radiation. An electron flood gun was used to control charging effects. Samples were prepared by compacting the catalyst powder on an In base (18). For all samples the measurement sequence and procedure was the same. The sequence of the spectral lines observed was $\mathrm{O}(1 s)$, Si $(2 p)$, Pt $(4 f)$, and $\mathrm{Au}(4 f)$. A $20-\mathrm{eV}$ range was recorded in each case. Signal intensity was obtained by integrating the area under the recorded peaks. It was felt that the most reliable comparison between samples would be obtained by using the Si $(2 p)$ intensity as an internal reference for each sample. In fact, it was found that the absolute magnitudes of the Si $(2 p)$ intensities for several of the samples ranged over a few percent only. By means of averaging values from several measurements a relative standard deviation of $\pm 1.5 \%$ was computed.

Catalytic activity for hydrogen transfer reactions was assessed by measuring the rate of the isotopic exchange reactions:

$$
\begin{aligned}
* \mathrm{C}_{6} \mathrm{H}_{6}(\mathrm{~g})+\mathrm{C}_{6} \mathrm{H}_{12}(\mathrm{~g}) \rightarrow & \mathrm{C}_{6} \mathrm{H}_{6}(\mathrm{~g}) \\
& +{ }^{*} \mathrm{C}_{6} \mathrm{H}_{12}(\mathrm{~g}), \\
\mathrm{H}_{2}(\mathrm{~g})+\mathrm{D}_{2}(\mathrm{~g}) & \rightarrow 2 \mathrm{HD}(\mathrm{g}),
\end{aligned}
$$

where ${ }^{*} \mathrm{C}$ is a carbon-14 atom.

A conventional flow system was employed for both reactions. 'The apparatus included metering valves, flow meters, gas purifying devices, constant temperature saturators and tubular reactor. It was operated at 1 atm total pressure. For reaction (1) known amounts of $\mathrm{BE}, \mathrm{CHA}$, and ${ }^{*} \mathrm{BE}$ were introduced into the reactor using $\mathrm{He}$ as a carrier gas. The rate of 
reaction (1) was measured under conditions of equilibrium for the hydrogenation of $\mathrm{BE}$,

$$
\mathrm{C}_{6} \mathrm{H}_{6}(\mathrm{~g})+3 \mathrm{H}_{2}(\mathrm{~g}) \rightarrow \mathrm{C}_{6} \mathrm{H}_{12}(\mathrm{~g}) \text {. }
$$

This condition was fulfilled by feeding to the reactor, in addition to $\mathrm{BE}$ and $\mathrm{CHA}$, $\mathrm{H}_{2}$ corresponding to the partial pressure in equilibrium (3). The establishment of reaction equilibrium (3) was asccrtained by analyzing the composition at the reactor inlet and the reactor outlet and obtaining similar values. Furthermore, whenever the $\mathrm{H}_{2}$ partial pressure in the feed was changed from the equilibrium value the reactor inlet and outlet compositions differed, indicating the occurrence of a net reaction (3). The reactor temperature was $205^{\circ} \mathrm{C}$, contact time in the range of 10 to $30 \mathrm{sec}$; from 1 to $3 \mathrm{~cm}^{3}$ of 100 to 170 -mesh catalyst (0.4-1.2 g) was employed. Product analysis for reaction (1) was performed by an in-line gas chromatograph (HP Model 5750 with flame detector) equipped with a 5 -ft column filled with $5 \% \mathrm{~B} 34+5 \%$ DIPP on Chrom-W (60-80 mesh). Fractions eluting from the g.c. were collected in a solution of PPO in toluene for liquid scintillation analysis. No side reactions were detected. Experiments were performed at various flow rates and gas phase compositions to ascertain the absence of diffusional limitations. For each set of conditions, several runs were carried out.
From these experiments it was estimated that the error in the rate coefficient $k_{\mathrm{c}}$ (see below) was $\pm 20 \%$ and in the pressure exponent $\mathrm{m}$ was $\pm 5 \%$.

For reaction (2) prepurified $\mathrm{H}_{2}$ and $\mathrm{D}_{2}$ (CP grade) were passed through $\mathrm{Pd}$ asbestos at $400^{\circ} \mathrm{C}$ and molecular sieve traps kept at liquid $\mathrm{N}_{2}$ temperature. High purity $\mathrm{N}_{2}$, employed as carrier gas, was further purified by passage through $\mathrm{Cu}$ turnings at $400^{\circ} \mathrm{C}$, followed by a liquid $\mathrm{N}_{2}$ molecular sieve trap. Reactor temperature was generally kept at $-78^{\circ} \mathrm{C}$. Gas analysis was carried out mass spectroscopically. The mass spectrometer (AEIMS10) was calibrated with known amounts of $\mathrm{H}_{2}$ and $\mathrm{D}_{2}$. The ms sensitivity for $\mathrm{HD}$ was assumed to be the average between that for $\mathrm{H}_{2}$ and for $\mathrm{D}_{2}$. Generally $10 \mathrm{mg}$ of catalyst mixed with $0.2 \mathrm{~g}$ of $\mathrm{SiO}_{2}$ were employed. A constant ratio $p_{\mathrm{D}_{2}} / p_{\mathrm{H}_{2}}=1$ was used throughout. From 2 to 4 runs were carried out for each set of conditions; the error in the rate coefficient $k_{\mathrm{D}}$ (see below) was estimated at $\pm 30 \%$.

\section{RESULTS}

\section{Catalyst Characterization}

$\mathrm{H}_{2}$ and $\mathrm{O}_{2}$ adsorption isotherms were measured on supported $\mathrm{Pt}$ and supported $\mathrm{Au}-\mathrm{Pt}$, while on $\mathrm{Au}$ the adsorption of $\mathrm{O}_{2}$ was carried out. $\mathrm{O}_{2}$ adsorption on $\mathrm{Au}$ was found to be a reliable method for the

TABLE 2

$\mathrm{H}_{2}$ and $\mathrm{O}_{2}$ Adsorption on $\mathrm{Pt}-\mathrm{SiO}_{2}$

\begin{tabular}{cccccc}
\hline $\begin{array}{c}\mathrm{Pt} \\
(\mathrm{wt} \%)\end{array}$ & $\left.\begin{array}{c}\mathrm{H}_{2} \text { uptake }^{a} \\
\mathrm{\textrm {cm } ^ { 3 } ( \mathrm { STP } )}\end{array}\right] \times 10^{2}$ & $\left.\begin{array}{c}\mathrm{O}_{2} \text { uptake } \\
\mathrm{g} \mathrm{cat}\end{array}\right]$ & $\left.\frac{\mathrm{O}_{2}{ }^{3}(\mathrm{STP})}{\mathrm{g} \text { cat }}\right] \times 10^{2}$ & $\begin{array}{c}\text { Percentage } \\
\mathrm{H}_{2}\end{array}$ & $\begin{array}{c}\text { Particle } \\
\text { diameter } \\
(\AA)\end{array}$ \\
\hline 0.26 & 4.73 & 8.5 & 1.8 & 32.1 & 35 \\
0.51 & 15.3 & 19.6 & 1.3 & 52.9 & 21 \\
1.14 & 24.0 & 30.3 & 1.3 & 36.8 & 31 \\
1.28 & 20.8 & - & - & 28.4 & 40 \\
3.25 & 57.8 & 80.1 & 1.4 & 31.0 & 37 \\
\hline
\end{tabular}

a $20^{\circ} \mathrm{C}, p_{\mathrm{H}_{2}} 0.15-0.20$ Torr.

${ }^{b} 200^{\circ} \mathrm{C}, p_{\mathrm{O}_{2}} 0.2-0.7$ Torr. 
TABLE 3

$\mathrm{H}_{2}$ and $\mathrm{O}_{2}$ Chemisorption on $\mathrm{Au}-\mathrm{Pt}-\mathrm{SiO}_{2}$ Preparations

\begin{tabular}{|c|c|c|c|c|c|c|c|c|}
\hline \multirow[t]{3}{*}{$\begin{array}{c}\text { Total metal } \\
\quad(\text { wt } \%)\end{array}$} & \multirow[t]{3}{*}{$\begin{array}{l}\text { Au overall } \\
\text { (atom } \% \text { ) }\end{array}$} & \multicolumn{2}{|c|}{$\mathrm{H}_{2}$ uptake $^{\alpha}$} & \multicolumn{2}{|c|}{$\mathrm{O}_{2}$ uptake $^{b}$} & \multicolumn{2}{|c|}{$\begin{array}{l}\text { Percentage } \\
\text { exposed }\end{array}$} & \multirow{3}{*}{$\begin{array}{c}\text { Surface } \\
\text { composition } \\
\text { (Au \%) }\end{array}$} \\
\hline & & g cat & $x$ & g cat & ג & $\mathrm{Pt}$ & $\mathrm{All}$ & \\
\hline & & & & Total metal & Au only & & & \\
\hline
\end{tabular}

\begin{tabular}{crrrrrrr}
\hline Series A & & & & & & & \\
0.59 & 70 & 1.46 & 3.50 & 1.60 & 14.5 & 13.7 & 69 \\
0.53 & 52 & 4.35 & 7.60 & 1.95 & 29.5 & 24.9 & 47 \\
0.83 & 23 & 10.30 & 17.40 & 4.01 & 28.0 & 74.2 & 44 \\
Series B & & & & & & & \\
6.13 & 89 & 3.96 & 7.30 & 2.15 & 10.0 & 1.53 & 52 \\
2.31 & 68 & 11.30 & 15.20 & 0.51 & 26.5 & 1.14 & 8 \\
1.40 & 45 & 14.20 & 19.70 & 1.24 & 32.2 & 6.92 & 15 \\
1.03 & 28 & 15.50 & 21.20 & 1.05 & 36.4 & 12.70 & 12 \\
\hline
\end{tabular}

a $20^{\circ} \mathrm{C}, p_{\mathrm{H}_{2}} 0.15-0.20$ Torr.

${ }^{b} 200^{\circ} \mathrm{C}, p_{\mathrm{D}_{2}} 0.2-0.7$ Torr.

calculation of the $\mathrm{Au}$ particle size (16). To obtain separate values of the surface area of the two metals in the bimetallic preparations, independent measurements of $\mathrm{O}_{2}$ adsorption and $\mathrm{H}_{2}$ adsorption were carried out. The assumption was made that the $\mathrm{H}_{2}$ and $\mathrm{O}_{2}$ stoichiometry found on supported Pt and the $\mathrm{O}_{2}$ stoichiometry found on supported $\mathrm{Au}$ did not change in the mixed $\mathrm{Au}-\mathrm{Pt}$ supported preparations. From the $\mathrm{H}_{2}$ uptake on $\mathrm{Au}-\mathrm{Pt}$, the percentage of $\mathrm{Pt}$ exposed was calculated using the adsorption stoichiometry Pt $+\frac{1}{2} \mathrm{H}_{2} \rightarrow \mathrm{Pt}-\mathrm{H}$. $\mathrm{II}_{2}$ chemisorption was measured at $20^{\circ} \mathrm{C}$ and $\mathrm{H}_{2}$ partial pressure of 0.15 to 0.20 Torr ( 1 Torr $=133.33 \mathrm{~N}$ $\mathrm{m}^{-2}$ ). No adsorption of $\mathrm{H}_{2}$ could be detected on the $\mathrm{SiO}_{2}$ support or on the $\mathrm{Au}$ preparation. The $\mathrm{O}_{2}$ adsorption was measured at $200^{\circ} \mathrm{C}$ and $\mathrm{O}_{2}$ partial pressure of 0.2 to 0.7 Torr. Under these conditions, $\mathrm{O}_{2}$ is chemisorbed on both Pt and Au. The $\mathrm{Pt}-\mathrm{O}$ surface stoichiometry at $200^{\circ} \mathrm{C}$ was established by using Pt catalysts of known surface area (determined by $\mathrm{H}_{2}$ chemisorption). The average $\left(_{2}\right.$ stoichiometry found at $200^{\circ} \mathrm{C}$ was

$$
\mathrm{Pt}+(1.3 / 2) \mathrm{O}_{2} \rightarrow \mathrm{Pt}-\mathrm{O}_{1,3}
$$

A summary of experimental results on $\mathrm{Pt}-\mathrm{SiO}_{2}$ is presented in Table 2. $\mathrm{O}_{2}$ adsorbed on $\mathrm{Au}$ in the $\mathrm{Au}-\mathrm{Pt}$ preparations was calculated by subtracting the amount of $\mathrm{O}_{2}$ adsorbed on $\mathrm{Pt}$, determined by the $\mathrm{Pt}-\mathrm{O}$ stoichiometry at $200^{\circ} \mathrm{C}$, from the total $\mathrm{O}_{2}$ uptake.

The percentage of $\mathrm{Au}$ exposed was calculated by using the $\mathrm{O}_{2}$ adsorption stoichiometry: $2 \mathrm{Au}+\frac{1}{2} \mathrm{O}_{2} \rightarrow \mathrm{Au}_{2} \mathrm{O}$. $\mathrm{Au}$ surface area derived from this stoichiometry were found to be consistent with the results from WAXS and Transmission Electron Micruscopy (16). In Table 3 the results obtained using the above procedure are reported. From the percentage exposed of both metals, the surface composition was calculated and it is reported in the last column of Table 3. The percentage of Pt exposed is plotted versus the overall composition in Fig. 1.

No $\mathrm{Pt}$ was detected in the WAXS analysis of Series A and Series B preparations. This is taken as an indication of small particle size of $\mathrm{Pt}$ in agreement with the conclusions from $\mathrm{H}_{2}$ adsorption (Table 2). An extensive Au-Pt alloying in clearly absent, since the lattice constant 
of $\mathrm{Au}$ in the $\mathrm{Au}-\mathrm{Pt}$ preparations was found to be similar to that of $\mathrm{Au}$. In contrast to $\mathrm{Pt}$, $\mathrm{Au}$ was easily detectable by WAXS (Table 4). In some Au preparations, diffraction from different crystal planes yielded different particle dimensions, indicating large anisotropy in particle growth. This effect was also reported in an earlier study of the supported $\Lambda u$ (19). Most likely, these observations are an indication of differences in nucleation and growth rate between $\mathrm{Au}$ and $\mathrm{Pt}$ particles. Indeed, the equivalent particle diameter of $\mathrm{Pt}$ in the $\mathrm{Au}-\mathrm{Pt}$ preparations, calculated from the $\mathrm{Pt}$ surface area, is one order of magnitude (or more) smaller than that of $\mathrm{Au}$, irrespective of bulk composition. This is taken as an indication that $\mathrm{Pl}$ nucleation was faster than that of $\mathrm{Au}$, and, consequently, local depletion of $\mathrm{Pt}$ salt during particle growth set in. These events will eventually lead to a mixed Au-Pt crystal particle.

Analysis of the ESCA results was carried out by dividing the areas of the $\mathrm{O}_{1 s}$, $\mathrm{Si}_{2 p}, \mathrm{Pt}_{4 f}$, and $\mathrm{Au}_{4 f}$ peaks, by the corresponding photoelectric cross sections (20), and expressing them as percentages. The percentage exposed of $\mathrm{Pt}$ and $\mathrm{Au}$ was calculated by means of the expression: $n=R / W \cdot K$ where $R$ is the metal-Si ratio, from ESCA peak ratios, $W$ is the weight percent of the metal, $D$ is the percentage exposed, and $K$ is a constant. The value of $K$, characteristic for each

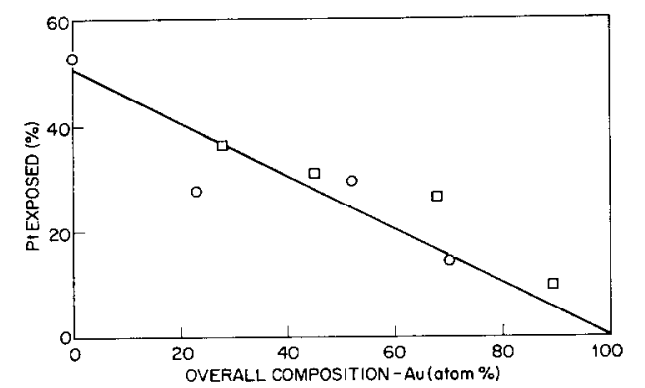

FIG. 1. Percentage of $\mathbf{P t}$ exposed from $\mathbf{H}_{2}$ chemisorption versus overall composition, in $\mathrm{SiO}_{2}$-supported Au-Pt; O, Series A ; $\square$, Series B.
TABLE 4

WAXS Characterization of $\mathrm{Au}-\mathrm{Pt}-\mathrm{SiO}_{2}$ Preparations

\begin{tabular}{|c|c|c|c|c|c|c|}
\hline \multirow{2}{*}{$\begin{array}{l}\text { Total } \\
\text { metal } \\
(w t \%)\end{array}$} & \multirow[t]{2}{*}{$\stackrel{\mathrm{Au}}{(\operatorname{atom} \%)}$} & \multicolumn{5}{|c|}{$\begin{array}{l}\text { Au crystallite diameter } \\
(\AA)\end{array}$} \\
\hline & & (111) & $(200)$ & $(220)$ & (311) & $(222)$ \\
\hline \multicolumn{7}{|l|}{ Series A } \\
\hline 0.55 & 100 & 450 & 347 & 261 & - & $\longrightarrow$ \\
\hline 0.59 & 70 & 450 & 335 & - & - & - \\
\hline 0.53 & 52 & 477 & 332 & - & $\longrightarrow$ & - \\
\hline 0.83 & 23 & 240 & - & - & - & - \\
\hline 0.51 & 0 & - & - & $\cdots$ & - & - \\
\hline \multicolumn{7}{|l|}{ Series B } \\
\hline 6.13 & 89 & 363 & 260 & 248 & 246 & 234 \\
\hline 2.31 & 68 & 242 & 230 & 212 & 213 & 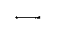 \\
\hline 1.40 & 45 & 215 & 180 & $\longrightarrow$ & - & - \\
\hline 1.30 & 28 & 318 & - & - & $\cdots$ & $\ldots$ \\
\hline
\end{tabular}

element, is obtained using a sample with known values of $W$ and $D$. From the percentage exposed of $\mathrm{Pt}$ and $\mathrm{Au}$ the surface composition was calculated (Table $5)$. The results obtained are plotted in Figure 2 together with the values of surface composition from $\mathrm{H}_{2}, \mathrm{O}_{2}$ chemisorption.

Hydrogen transfer between benzene and cyclohexane. It is assumed that reaction (1) takes place via the following sequence of adsorption-deposition steps (1):

$$
\begin{gathered}
{ }^{*} \mathrm{C}_{6} \mathrm{H}_{6}(\mathrm{~g})+6 \mathrm{H}(\mathrm{s}) \rightarrow{ }^{*} \mathrm{C}_{6} \mathrm{H}_{12}(\mathrm{~g}), \\
\mathrm{C}_{6} \mathrm{H}_{12}(\mathrm{~g}) \rightarrow \mathrm{C}_{6} \mathrm{H}_{6}(\mathrm{~g})+6 \mathrm{H}(\mathrm{s}) .
\end{gathered}
$$

Since reaction step (1b) is the reverse of reaction step (1a) and equilibrium condilions prevailed during the course of reaction (1), the rate of the latter and the

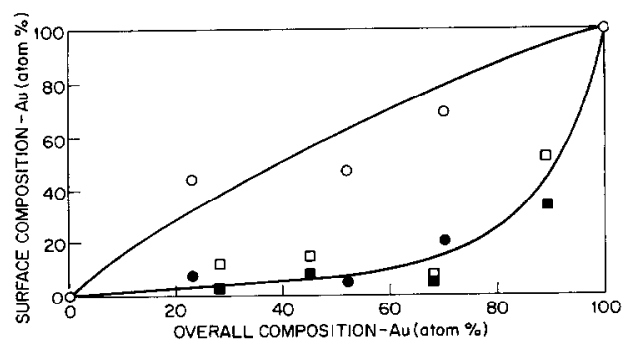

FIg. 2. Surface versus overall composition of $\mathrm{SiO}_{2}$-supported $\mathrm{Au}-\mathrm{Pt}$ particles. Series A: O, by $\mathrm{H}_{2}, \quad \mathrm{O}_{2}$ chemisorption; $\bullet$, by ESCA. Series $\mathrm{B}$ : $\square$, by $\mathrm{H}_{2}, \mathrm{O}_{2}$ chemisorption; $\mathbf{a}$, by IASCA. 
TABLE 5

ESCA Characterization of $\mathrm{Au}-\mathrm{Pt}-\mathrm{SiO}_{2}$ Preparations

\begin{tabular}{ccc}
\hline $\begin{array}{c}\text { Total metal } \\
(\text { wt } \%)\end{array}$ & $\begin{array}{c}\text { Au overall } \\
\text { (atom } \%)\end{array}$ & $\begin{array}{c}\text { Surface composition } \\
\text { (Au atom } \%)\end{array}$ \\
\hline Series A & & \\
0.55 & 100 & 100 \\
0.59 & 70 & 20 \\
0.53 & 52 & 5 \\
0.83 & 23 & 8 \\
0.51 & 0 & 0 \\
Series B & & \\
6.13 & 89 & 34 \\
2.31 & 68 & 6 \\
1.40 & 45 & 8 \\
1.03 & 28 & 3
\end{tabular}

a Calculated by means of the expression $1 /(1$ $\left.+D_{\mathrm{Pt}}(\mathrm{Pt})_{\mathrm{t}} / D_{\mathrm{Au}}(\mathrm{Au})_{\mathrm{t}}\right)$, where $D_{\mathrm{P} \mathrm{t}}, D_{\mathrm{Au}}$ are the Pt and $\mathrm{Au}$ dispersion, respectively, and $(\mathrm{Pt})_{\mathrm{t}},(\mathrm{Au})_{\mathrm{t}}$ are the total Pt and Au atoms, respectively.

rates of reaction steps (1a) and (1b) are similar. Considering reaction step (1a), its rate is given by:

$$
\frac{1}{W} \frac{d n *_{\mathrm{CHA}}}{d t}=k_{\mathrm{c}} p_{*_{\mathrm{BE}}}-k_{\mathrm{c}}^{\prime} p_{*_{\mathrm{CHA}}}
$$

where $W, n_{* \mathrm{CHA}}, p_{* \mathrm{~B} \mathrm{E}}$, and $p_{* \mathrm{CHA}}$ are the catalyst weight, moles of ${ }^{*} \mathrm{CHA}$, and partial pressures of ${ }^{*} \mathrm{BE}$ and ${ }^{*} \mathrm{CHA}$, respectively, and $k_{v^{\prime}} k^{\prime}$ : are the forward and reverse rate coefficients of reaction step (1a). Introducing the equilibrium condition and integrating Eq. (4) for a flow reactor one obtains (1):

$$
\begin{array}{r}
k_{\mathrm{c}}=\frac{\dot{V}}{W R T} \frac{1}{1+1 / \beta} \ln \frac{1}{1-\alpha_{\mathrm{e}}} \\
{\left[\frac{\operatorname{moles}}{\mathrm{g} \times \mathrm{sec} \times \mathrm{atm}}\right],}
\end{array}
$$

where $\dot{V}$ is the total volumetric fow rate measured at the temperature $T, R$ is the gas constant, $\beta=p_{\mathrm{CHA}} / p_{\mathrm{BE}}$, the reaction conversion $\alpha_{\varepsilon}=p_{* \mathrm{CHA}} /\left(p_{* \mathrm{CHA}}\right)_{e}$; the suffix $e$ refers to equilibrium conditions. The

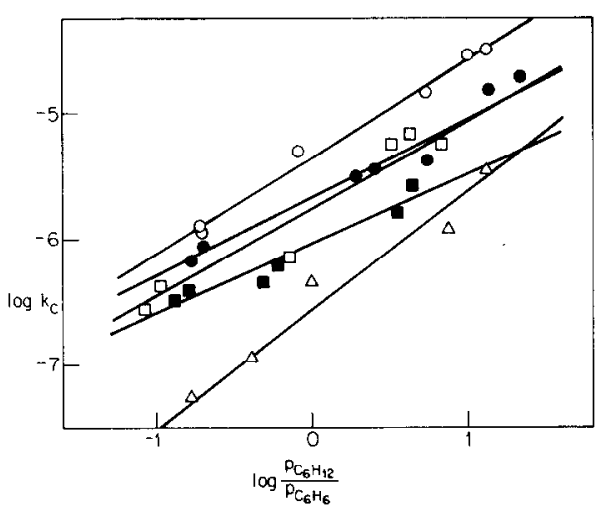

FIa. 3. Rate coefficient, $k_{e}$, for reaction (1) as a function of $\beta=p_{\mathrm{CHA}} / p_{\mathrm{BE}}, 205^{\circ} \mathrm{C}$, catalyzed by Au-Pt-SiO 2 ; Series A: $0,0.51$ wt $\% \mathrm{Pt} ; \bullet ; 0.61$ wt $\% \mathrm{Au}-\mathrm{Pt} ; \square, 0.83$ wt\% Au-Pt; $\square, 0.53 \mathrm{wt} \%$ A $1-\mathrm{Pt} ; \triangle, 0.59 \mathrm{wt} \%$ Au-Pt.

influence of the gas phase composition $\beta$, upon the rate coefficient $l_{i}$, for catalysts of Series A at $205^{\circ} \mathrm{C}$ is shown in Fig. 3 . Similar results for Series B catalysts and for $\mathrm{Pt}-\mathrm{SiO}_{2}$ are reported in Figs. 4 and 5 . In all cases, $k_{\mathrm{c}}$ increased with $\beta$.

In the derivation of the Eq. (4), the reaction rate was assumed to be first order in $p_{* \mathrm{BE}}$ and $p_{* \mathrm{CHA}}$. The actual dependence is obtained from rate measurements at

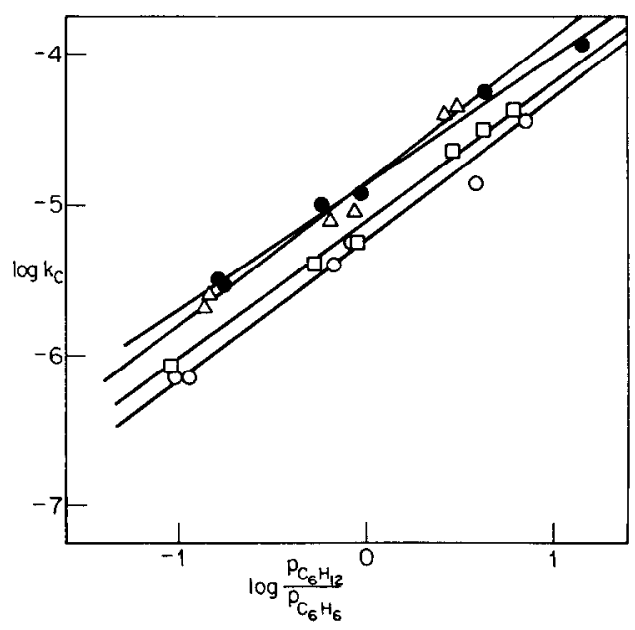

Fig. 4. Rate coefficient, $k_{\text {e }}$, for reation (1) as a function of $\beta=p_{\mathrm{CHA}} / \rho_{\mathrm{BE}}, 205^{\circ} \mathrm{C}$, catalyzed by Au-Pt-SiO ${ }_{2}$, Series B: O, 6.13 wt $; \triangle, 2.31 \mathrm{wt} \%$ $\Lambda u-P t ; \bullet, 1.40 \mathrm{wt} \%$ Au-Pt; $\square, 1.03 \mathrm{wt} \% \Lambda \|-P \mathrm{t}$. 
various $\beta$ 's. The results are expressed by means of the equation

$$
k_{\mathrm{c}}=k_{\mathrm{c}}{ }^{\mathrm{o}} \beta^{m}
$$

where $k_{c}{ }^{\circ}$ is the rate constant for reaction (1) and $0<m<1$. The values of $k_{\mathrm{c}}{ }^{\circ}$ and $m$ calculated from Eq. (6) are reported in Table 6 for all three set of catalysts examined. Under the experimental condition used, the rate of reaction (1) on $\mathrm{Au}$ was found to be negligible.

$\mathrm{H}_{2}-\mathrm{D}_{2}$ equilibration. Since the results on the rate of reaction (2) showed that the rate increased with $\left(p_{\mathrm{H}_{2}}\right)_{\text {total }}$, it was assumed that a likely reaction scheme was the following:

$$
\begin{aligned}
& \mathrm{H}_{2}(\mathrm{~g})+\mathrm{D}(\mathrm{s}) \rightarrow \mathrm{HD}(\mathrm{g})+\mathrm{H}(\mathrm{s}) \\
& \mathrm{D}_{2}(\mathrm{~g})+\mathrm{H}(\mathrm{s}) \rightarrow \mathrm{HD}(\mathrm{g})+\mathrm{D}(\mathrm{s}) .
\end{aligned}
$$

Consider the rate of reaction step (2a)

$$
\frac{V}{W R T} \frac{d p_{\mathrm{HD}}}{d t}=k_{\mathrm{D}} p_{\mathrm{H}_{2}}-k_{\mathrm{D}}^{\mathrm{b}} p_{\mathrm{HD}}
$$

where $V, k_{\mathrm{D}}, k_{\mathrm{D}}^{\mathrm{b}}$ are the volume of the catalyst bed and the forward and backward rate coefficient of reaction step (2a),

TABLE 6

Rate Constant, $k_{\mathrm{c}}{ }^{\circ}$, [Eq. (6)], Exponet $m$ [Eq.(6)], Surface Collision Efficiency $\gamma_{c}[$ Eq. (10)], for Reaction (1) Catalyzed by $\mathrm{Pt}-\mathrm{SiO}_{2}$ and $\mathrm{Au}-\mathrm{Pt}-\mathrm{SiO}_{2}$ Preparations, $205^{\circ} \mathrm{C}$

\begin{tabular}{lcccc}
\hline $\begin{array}{c}\text { Total } \\
\text { metal } \\
(\text { wt\% })\end{array}$ & $\begin{array}{c}\mathrm{Au} \\
\text { (atom \%) }\end{array}$ & {$\left[\begin{array}{c}k_{\mathrm{e}^{\circ}} \\
\text { molecules }\end{array}\right]$} & $m$ & $\gamma_{\mathrm{e}} \times 10^{9}$ \\
\hline 0.26 & - & 0.47 & 0.79 & 4.75 \\
0.51 & - & 0.29 & 0.76 & 2.93 \\
1.28 & - & 0.42 & 0.76 & 4.25 \\
3.25 & - & 0.20 & 0.81 & 2.02 \\
Series A & & & & \\
0.55 & 100 & $a$ & $a$ & $a$ \\
0.59 & 70 & 0.22 & 0.94 & 2.22 \\
0.53 & 52 & 0.33 & 0.56 & 3.34 \\
0.83 & 23 & 0.15 & 0.73 & 1.52 \\
0.51 & 0 & 0.29 & 0.76 & 2.93 \\
Series B & & & & \\
6.13 & 89 & 1.64 & 0.95 & 16.58 \\
2.31 & 68 & 1.39 & 0.94 & 14.05 \\
1.40 & 45 & 1.12 & 0.83 & 11.32 \\
1.03 & 28 & 0.45 & 0.94 & 4.55 \\
\hline
\end{tabular}

a No detectable reaction on $\mathrm{Au}$.

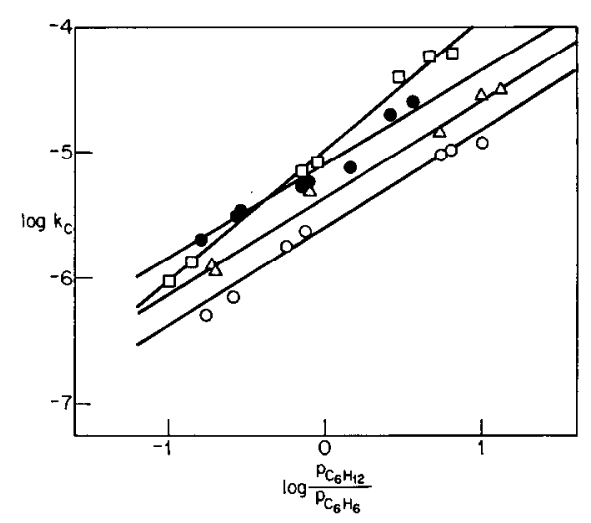

FIG. 5. Rate coefficient, $k_{\mathrm{c}}$, for reaction (1) as a function of $\beta=p_{\mathrm{CHA}} / p_{\mathrm{BE}}, 205^{\circ} \mathrm{C}$, catalyzed by $\mathrm{Pt}-\mathrm{SiO}_{2} ; 0,0.26 \mathrm{wt} \% \mathrm{Pt} ; \triangle, 0.51$ wt $\% \mathrm{Pt}$; $\bullet, 1.28 \mathrm{wt} \% \mathrm{Pt} ; \square, 3.25 \mathrm{wt} \% \mathrm{Pt}$.

respectively. Introducing the reaction conversion $\alpha_{\mathrm{D}}=\left(\gamma_{\mathrm{t}}-\gamma_{0}\right) /\left(\gamma_{\mathrm{e}}-\gamma_{0}\right)$, where $\gamma=p_{\mathrm{HD}} /\left(p_{\mathrm{H}_{2}}\right)_{0}$, eliminating $k_{\mathrm{D}}^{\mathrm{b}}$ and integrating, Eq. (7) yields:

$k_{\mathrm{D}}=\frac{V}{W R T_{\tau}} \gamma_{\mathrm{e}} \ln \frac{1}{1-\alpha_{\mathrm{D}}}\left[\frac{\text { moles }}{\mathrm{g} \text { atm sec }}\right]$,

where $\tau$ is the contact time.

The validity of $\mathrm{Eq}$. (7) was tested at various $\tau$ 's and the calculated values of $k_{\mathrm{D}}$ were found to be within $\pm 30 \%$. Typical values of $k_{\mathrm{D}}$ for catalyst 2.31 wt $\%$ $(68 \% \mathrm{Au})$ on $\mathrm{SiO}_{2}$ at $-78^{\circ} \mathrm{C}$ are plotted versus $\left(p_{\mathrm{H}_{2}}\right)_{\text {total }}$ in Fig. 6. The values of the rate constant $k_{\mathrm{D}}{ }^{\mathrm{o}}$ for both series of

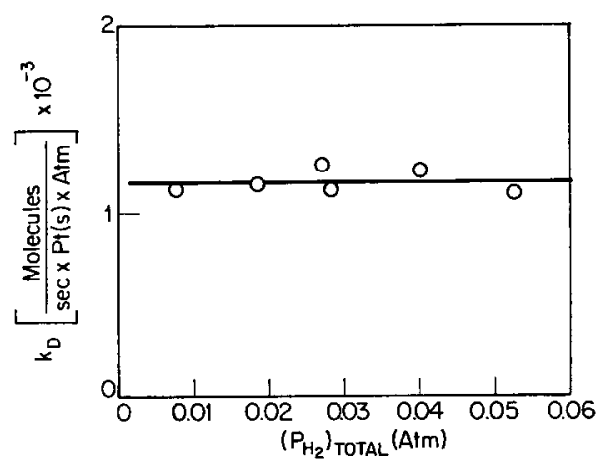

FIG. 6. Rate coefficient, $k_{\mathrm{D}}$, for reaction (2) as a function of $\left(p_{\mathrm{H}_{2}}\right)_{\text {total }},-78^{\circ} \mathrm{C}$, catalyzed by 2.31 wt $\%$ Au-Pt on $\mathrm{SiO}_{2}$. 
TABLE 7

Rate Constant for Reaction (2), $k_{\mathrm{D}} \mathrm{o}^{\mathrm{o}}$, and Collision Efficiency $\gamma_{\mathrm{D}}$, for $\mathrm{Au}-\mathrm{Pt}-\mathrm{SiO}_{2}$ Preparations,

$$
T=-78^{\circ} \mathrm{C}
$$

\begin{tabular}{|c|c|c|c|}
\hline $\begin{array}{l}\text { 'Total metal } \\
\qquad(\mathrm{wt} \%)\end{array}$ & $\stackrel{\mathrm{Au}}{(\operatorname{atom} \%)}$ & {$\left[\frac{k_{\mathrm{I}^{\circ}}}{\text { molecules }}\right]$} & $\left.\gamma_{1}\right) \times 10^{7}$ \\
\hline \multicolumn{4}{|l|}{ Series $A$} \\
\hline 0.55 & 100 & - & 一 \\
\hline 0.59 & 70 & 525 & 5.4 \\
\hline 0.53 & 52 & 575 & 6.0 \\
\hline 0.83 & 23 & 630 & 5.5 \\
\hline 0.51 & 0 & 1130 & 11.7 \\
\hline \multicolumn{4}{|l|}{ Series B } \\
\hline 6.13 & 89 & 775 & 8.0 \\
\hline 2.31 & 68 & 1150 & 11.9 \\
\hline 1.40 & 45 & 1300 & 13.5 \\
\hline 1.03 & 28 & 625 & 6.4 \\
\hline
\end{tabular}

Au-Pt preparations are reported in Table 7. $K_{\mathrm{D}}{ }^{\circ}$ is defined by the expression $k_{\mathrm{D}}=k_{\mathrm{D}}{ }^{\circ}$ $\left(p_{\mathrm{H}_{2}}\right)_{\text {total }}{ }^{\mathbf{n}}(9)$. In all cases the value of $n=0$. In the range $10<p_{\mathrm{H}_{2}}<100$ Torr, $-78<T<30^{\circ} \mathrm{C}$ the calculated activation energies were 2.5 to $3.0 \mathrm{kcal} / \mathrm{mole}$. This value is to be compared with earlier determinations on wire, sponge, and $\mathrm{Pt}$ black ranging between 0.5 to $7.5 \mathrm{kcal}$ mole (21), between 0.5 to 3.0 (21) kcal/ mole on $\mathrm{Pt}-\mathrm{SiO}_{2}$ and between 2.5 to 3.0 $\mathrm{kcal} / \mathrm{mole}(2 \mathscr{2})$ on $\mathrm{Pt}$ films.

\section{DISCUSSION}

\section{Catalyst Characterization}

The significant experimental results reported in the previous section on catalyst characterization are:

1. In Series $A$ and $B$, the addition of $A u$ caused a decrease in the percentage of $\mathrm{Pt}$ exposed (Fig. 1) ;

2. Pt crystallites and Au-Pt alloy formation could not be detected by WAXs;

3. largely nonspherical $\mathrm{Au}$ particles, with size ranging between 200 and $500 \AA$, have been detected by WAXS. Particles became more spherical as the Au content increased;

4. the surface compositions in Series $B$ preparations deduced from $\mathrm{H}_{2}$ and $\mathrm{O}_{2}$ chemisorption and from ESCA were similar and indicated a $\mathrm{Pt}$ enrichment at the surface (Fig. 2). In Series A the $\mathrm{H}_{2}$ and $\mathrm{O}_{2}$ chemisorption yielded a surface composition higher in $\mathrm{Au}$ than that deduced from ESCA (Fig. 2).

Results under item 1 may be explained by means of two hypotheses, namely, that (a) upon increasing the amount of $\mathrm{Au}$, Pt particle size increased and the percentage of $\mathrm{Pt}$ exposed decreased; (b) particles of mixed $\mathrm{Au}$ and $\mathrm{Pt}$ were formed and $\mathrm{Au}$ covered Pt. Since Pt crystallites with size $\widetilde{>} 25 \AA$ could not be detected by WAXS (item 2 above), hypothesis (a) may be ruled out.

In earlier studies on $\mathrm{SiO}_{2}$ supported $\Lambda \mathrm{u}-\mathrm{Pt}$ catalysts, it was found that alloy formation could be achieved by coreduction of the mixed $\mathrm{Au}$ and $\mathrm{Pt}$ salt solution at $80^{\circ} \mathrm{C}$ with hydrazine but not by support coimpregnation and high temperature $\left(450^{\circ} \mathrm{C}\right)$ reduction with $\mathrm{H}_{2}$. The coimpregnation catalysts did not show alloying even after treatment at $610^{\circ} \mathrm{C}$ for 84 hours (3). However, if oxidation at $77^{\circ} \mathrm{C}$ and reduction at $200^{\circ} \mathrm{C}$ were repeatedly performed on the coimpregnated catalysts, alloy formation was obtained (4).

Since from the WAXS spectra of $\mathrm{Au}$ there was no evidence of alloy formation (item 2 above), we conclude that two kinds of particles were present containing aggregates of $\mathrm{Au}$ and $\mathrm{Pt}$ atoms and of $\mathrm{Au}$ atoms only. There was no direct evidence for the presence of particles containing Pt atoms only. The Au aggregates were considerably larger than those containing Pt and $\mathrm{Au}$. We envision that, initially, both metals nucleated separately on the support surface; assuming that Pt had a faster nucleation rate than $\mathrm{Au}$, a larger number of Pt embryos were formed. At a later stage of the particle formation as a consequence of local enrichment in the $\mathrm{Au}$ salt, and/or higher mobility of Au particles already formed (lower melting point and/or 
higher vapor pressure, whichever transport mechanism may have been responsible for $\mathrm{Au}$ aggregation) deposition of Au upon the Pt particles occurred.

The presence of particles containing atomic aggregates of $\mathrm{Au}$ and $\mathrm{Pt}$ raises the question of composition of their surface. To this end we shall compare the results from $\mathrm{H}_{2}$ chemisorplion and from ESCA. Since we estimate that the ESCA sampling depth was about $12 \AA$, a comparison between the percentage of $\mathrm{Pt}$ exposed derived from ESCA and that obtained from $\mathrm{H}_{2}$ chemisorption is indicative of the compositional profile in the immediate subsurface. In contrast to the samples of Series B, in those of Series A the composition was not uniform. The comparison may be easily carried out using the results presented in Fig. 2 . Indeed, inspection of Fig. 2 shows that for Series A samples, there was disagreement between surface composition from chemisorption and from ESCA.

In conclusion, Series A and B preparations included particles of mixed $\mathrm{Au}-\mathrm{Pt}$ aggregates, of individual $\mathrm{Au}$ aggregates and, likely, of individual $\mathrm{Pt}$ aggregates also. The central part of the mixed $\mathrm{Au}-\mathrm{Pt}$ particles was constituted by $\mathrm{Pt}$ or by a Pt-rich $\Lambda \mathbf{u}-\mathrm{Pt}$ alloy. In Serics $\Lambda$ preparation, an $\mathrm{Au}$ enrichment at the surface layer was found, but it was not clear how morphologically this enrichment was distributed at the surface itself (uniform layer versus rafts or islands). Thus, depending upon the interplay of conditions prevailing during particle formation and growth, subtle variations in composition and local morphology at the surface of mixed aggregates of $\mathrm{Au}$ and $\mathrm{Pt}$ were induced into preparations possessing similar overall $\mathrm{Au} / \mathrm{Pt}$ ratios. Since the single different condition between Series $A$ and Series B was the concentration of the original salt solution, there is a strong implication that the dissimilar surface composition obtained in the two series

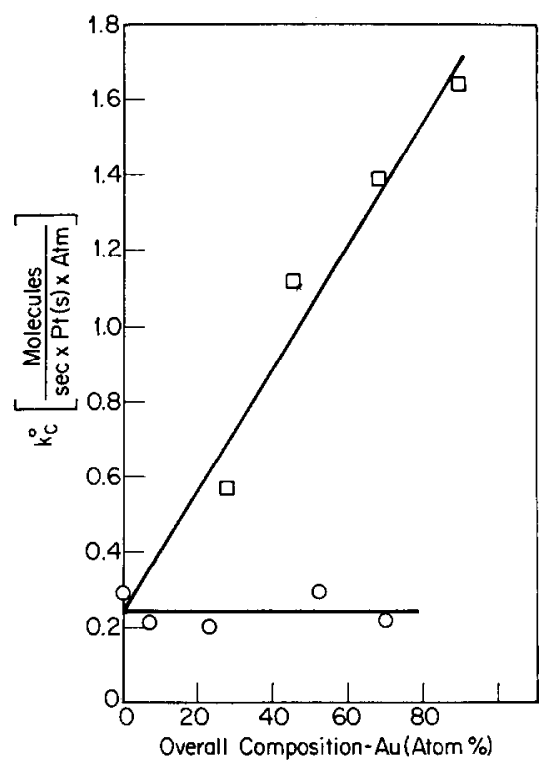

FIG. 7. Rate constant, $k_{0}{ }^{\circ}$, for reaction (1) [Eq. (6)] versus overall composition in $\mathrm{Au}-\mathrm{Pt}-\mathrm{SiO}_{2}$ preparation, $205^{\circ} \mathrm{C}$; $O$, Series A : $\square$, Series B.

reflects the interplay of the nucleation and growth rates of the two metals at the support surface.

Hydrogen transfer between $B E$ and $C H A$. The significant conclusions which may be derived from an inspection of Figs. 3, 4, and 5 and Table 6 are the following:

(a) Reaction (1) took place readily at $205^{\circ} \mathrm{C}$ under the conditions of reaction equilibrium (3) on all catalysts investigated, except for Au. There was no detectable presence of side reactions;

(b) the rate of reaction increased with the ratio $\beta=p_{\mathrm{CHA}} / p_{\mathrm{BE}}$ (Figs. $\left.3,4,5\right)$;

(c) catalysts of Series A and B showed differences in the reaction rate (Table 6). The activity of catalysts of Series A, when expressed in terms of surface Pt atoms, was independent of the overall particle composition and similar to that measured for supported Pt, while that of Series B increased with increasing $\mathrm{Au}$ content (Fig. 7);

(d) in $\mathrm{Pt}-\mathrm{SiO}_{2}$ the rate of reaction was independent of the amount of Pt (Table 6); 


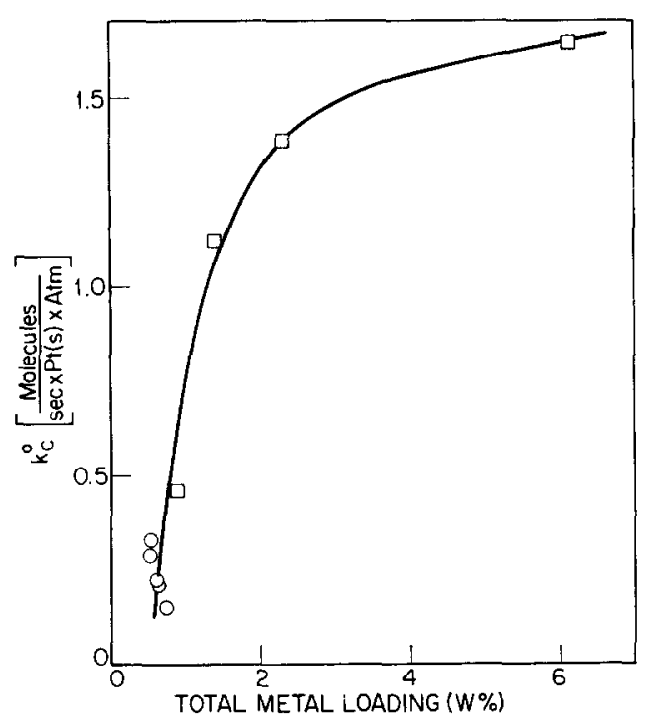

Fig. 8. Total amount of metal and rate constant, $k_{0}{ }^{\circ}$ for reaction (1) in $\mathrm{Au}-\mathrm{Pt}-\mathrm{SiO}_{2}$ catalysts ; O, Series A; $\square$, Series B.

(e) for all catalysts studied the value of $m$ (Eq. 6) was constant over a range of $\beta$ of about two orders of magnitude, and $0.56<m<0.95$ (Table 6).

Results under (a) are consistent with earlier conclusions on the rate of reaction (1) over several noble metal catalysts, which showed comparable activity at temperatures as low as $117^{\circ} \mathrm{C}$ (1). The only difference between the two studies is in the value of the equilibrium hydrogen partial pressure; in the earlier investigation the hydrogen partial pressure was on the order of $10^{-3}$ Torr, molecular $\mathrm{H}_{2}$ was not fed with $\mathrm{BE}$ and $\mathrm{CHA}$. In the present study, because of the higher temperature and the desirability of directly assessing the establishment of equilibrium (3), molecular hydrogen corresponding to the equilibrium partial pressure of reaction (3) was fed with BE and CHA. Also, in the earlier work it was found that the reaction rate increased with $\beta$ [item (e) above]. The fact that the activity of Series A catalysts was independent of the $\mathrm{Au}$ content and similar to that of supported l't only indicates that $\mathrm{P} t$ sites responsible for the reaction were similar, geometrically and energetically, on all these catalysts. The compelling conclusion is that $\mathrm{Au}$ simply acted as a diluent and no interaction between $\mathrm{Au}$ and $\mathrm{Pt}$ was evident. This role of $\mathrm{Au}$ is consistent with previous studies on Au-Pt films and foils (10).

This situation, however, is not reflected in the activity of catalysts of Series B. In these preparations increasing overall $\mathrm{Au}$ content increased their catalytic activity. At the $\mathrm{Au} / \mathrm{Pt}$ ratio of $7 / 3$, the value of $k_{\mathrm{e}}{ }^{\circ}$ on Series B was seven times higher than the value on the catalyst of similar $\mathrm{Au} / \mathrm{l}$ t ratio from Series $\mathrm{A}$. It should be mentioned that in previous studies on supported $\mathrm{Ru}-\mathrm{Cu}$ and $\mathrm{Os}-\mathrm{Cu}$ catalysts for ethane and cyclohexane hydrogenolysis, it was found that the activity (per surface $\mathrm{Ru}$ atom) decreased with increasing $\mathrm{Cu}$, while it was not modified for cyclohexane dehydrogenation (23).

It is tempting to relate the effect of $\mathrm{Au}$ on catalytic activity of Series B to the subtle differences, as exemplified by the homogeneous composition of the surface layers of the mixed $\mathrm{Au}-\mathrm{Pt}$ particles found in preparations $B$ in contrast to the nonhomogeneous composition of Series A and discussed in the previous section. The analysis of the experimental results does not permit a detailed topological description of the differences in composition. It is, however, conceivable that the compositional homogeneity of Series B formed the basis for $\mathrm{Au}-\mathrm{Pt}$ interaction which modified the surface reactivity of $\mathrm{Pt}$. In earlier studies on supported $\mathrm{Fe}-\mathrm{Pt}$ catalysts, it was concluded that the extent of formation of mixed aggregate of $\mathrm{Fe}$ and Pt varied monotonically with the Fe concentration at constant $\mathrm{Pt}$ concentration (24). If a similar effect was present in the $\mathrm{Au}-\mathrm{Pt}$ supported preparations, it may be concluded that the extent of the interaction between $\mathrm{Pt}$ t and $\mathrm{Au}$ should increase with the amount of $\mathrm{Au}$ at constant $\mathrm{Pt}$ content. The results of the reaction rate 
constant plotted against total metal content for Series A and B support this contention (Fig. 8). Further insight into the $\mathrm{Au}-\mathrm{Pt}$ interaction may be obtained by consideration of the work function of $\mathrm{Pt}$ and its variation upon additions of $\mathrm{Au}$. From previous work function measurements on equilibrated $\mathrm{Au}-\mathrm{Pt}$ films (12) it may be concluded that upon additions of $\mathrm{Au}$ to $\mathrm{Pt}$ the Fermi level of $\mathrm{Pt}$ increases quite sharply initially, leveling off for larger Au additions. We shall assume that in our preparations whenever an electronic interaction between $\mathrm{Au}$ and $\mathrm{Pt}$ sets in, it involved the raising of the Fermi level of $\mathrm{Pt}$ with increasing amount of $\mathrm{Au}$. To find out the effect of the resulting more electron rich $\mathrm{Pt}$ surface site on the catalytic activity of the site for reaction (1) we need to turn to information derived from the exponent $m$ [Eq. (6)]. To this end, we shall consider that the rate of reaction (1) increased with $\beta$ ( $m$ positive) indicating that the concentration of the controlling surface intermediate increased with the ratio $p_{\mathrm{CHA}} / p_{\mathrm{BE}}$. In the reaction sequence (1a), (1b) the intermediate has been formally indicated as $\mathrm{H}(\mathrm{s})$, electronically, however, it may involve both $\mathrm{CHA}$ and $\mathrm{BE}$. We shall assume that the bonding of this intermediate included electron backdonation from the metal to the adsorbate. Finally, it should be realized that the value of $m$ governed the nature of the adsorption isotherm,

$$
[\mathrm{H}(\mathrm{s})] \propto\left(p_{\mathrm{CHA}} / p_{\mathrm{BE}}\right)^{m},
$$

in such a way that for a given $p_{\mathrm{CHA}} / p_{\mathrm{BE}}$ ratio, $[\mathrm{H}(\mathrm{s})]$ increased with $m$. Since the value of $[\mathrm{H}(\mathrm{s})]$ corresponded to the fraction of surface covered under a given $p_{\mathrm{CHA}} / p_{\mathrm{BE}}$ ratio, we may employ the values of $m$ to ascertain variations in surface coverage of the reactive intermediate.

We have now the possibility to explore qualitatively the effect of a more electron rich $\mathrm{Pt}$ site (as a consequence of $\mathrm{Au}$ interaction) on the rate of reaction (1).
Indeed, under the conditions described, raising the $\mathrm{Pt}$ Fermi level increased the coverage of the surface, since more electrons flow into the lower-lying surface level of the adsorbate, whose energy was fixed by the $p_{\mathrm{CHA}} / p_{\mathrm{BE}}$ ratio which was held constant throughout the course of reaction (1). An increase in surface coverage upon additions of $\mathrm{Au}$ to $\mathrm{Pt}$ should result, as indicated previously, in a higher $m$ value. We turn now to the computations reported in Table 6 . The average value of $m$ for $\mathrm{Pt}$ is 0.77 , while for Series $\mathrm{B}$ it is 0.92. The change is in the expected direction. For Series $A$ the average value of $m$ is 0.75 . For the latter series, in which no evidence of $\mathrm{Au}-\mathrm{Pt}$ interaction was found, the value of $m$ is practically similar to that for Pt. This is considered significant.

The reaction collision efficiency, $\gamma_{e}$, was calculated with the aid of the expression (1)

$$
\gamma_{\mathrm{c}}=k_{\mathrm{e}}{ }^{\mathrm{o}}(2 \pi M k T)^{\frac{1}{2}},
$$

where $M$ and $k$ are the average molecular mass and the Boltzman constant, respectively. The computed values are collected in Table 6 . The values ranging between about ( 1 to 15$) \times 10^{-9}$ are an indication of the low probability of occurrence of reaction (1).

$\mathrm{H}_{2}-\mathrm{D}_{2}$ equilibration. The results reported in Fig. 6 and in Table 7 may be summarized as follows:

1. The rate of the $\mathrm{H}_{2}-\mathrm{D}_{2}$ equilibration at $-78^{\circ} \mathrm{C}$ was first order in $\left(p_{\mathrm{H}_{2}}\right)_{\text {total }}$;

2. when expressed in terms of surface Pt atoms, the catalytic activity of Series $\Lambda$ and Series $B$ was quantitatively similar;

3. the activity was independent of the overall composition of the sample (Fig. 9) ;

4. surface collisional efficiencies at $-78^{\circ} \mathrm{C}$ were about $10^{-7}$, or two orders of magnitudes higher than those for reaction (1) at $205^{\circ} \mathrm{C}$.

These conclusions have a rather simple and direct interpretation. Indeed, assuming 


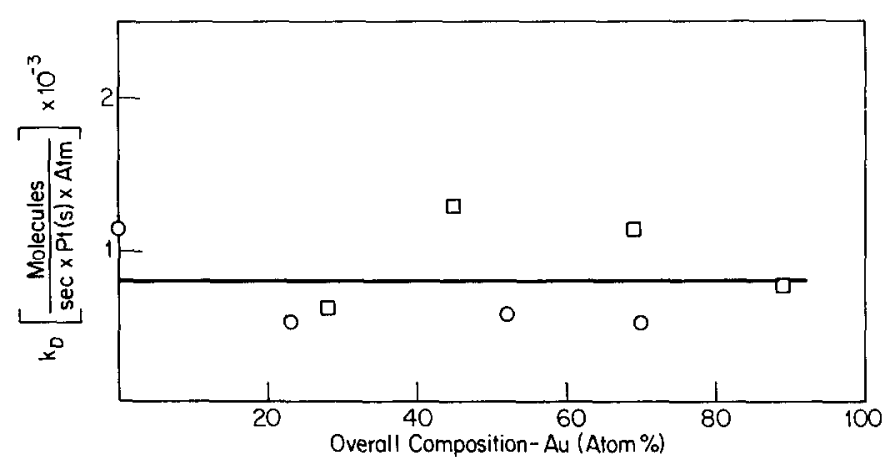

Fig. 9. Rate Constant, $k_{\perp^{\circ}}$, for reaction (2) and overall composition in $\mathrm{Au}-\mathrm{Pt}-\mathrm{SiO}_{2}$ preparations, $-78^{\circ} \mathrm{C}, 10<\left(p_{\mathrm{H}_{2}}\right)_{\text {total }}<100$ Torr, $p_{\mathrm{H}_{2}} / p_{\mathrm{D}_{2}}=1$; O, Series A; $\square$, Series B.

that $\mathrm{H}_{2}$ adsorption is represented by the reaction $\mathrm{H}_{2} \rightleftharpoons 2 \mathrm{H}$, its Langmuir formulation gives $\theta=b p_{\mathrm{H}_{2}}^{\frac{1}{2}} / 1+b p_{\mathrm{H}_{2}}{ }^{\frac{1}{2}}$, where $\theta$ is the fraction of surface covered by $\mathrm{H}_{2}$ and $b$ the adsorption equilibrium constant. Taking $b p_{\mathrm{H}_{2}}{ }^{\frac{1}{2}} \gg 1, \theta \cong$ constant and the rate of reaction (2) $\propto \theta p_{\mathrm{H}_{2}}=\propto p_{\mathrm{H}_{2}}$ (item 1 above). The possible influence of electronic interactions between $\mathrm{Au}$ and $\mathrm{Pt}$ on the surface population of the reactive intermediate cannot be kinetically detected whenever the steady state surface coverage corresponds to a bare or to a fully covered surface. The experimental observation that in this instance $n=0$ (Eq. (9)) indicates that reaction (2) took place on a fully covered surface. Collision efficiencies at $-78^{\circ} \mathrm{C}$ were about two orders of magnitude higher than the collision efficiencies recorded for reaction (1) at $250^{\circ} \mathrm{C}$.

\section{CONCIUSION}

The concept of sensitivity of a catalytic reaction to the structure of a surface implies the requirement for surface sites with specific coordination and characteristic two-dimensional structure. As the results of this study have shown, reaction. (1) can be sensitive and insensitive to the composition of the surface layers and, consequently, to the structure of $\mathrm{Pt}$ aggregates in these layers. It has been argued that the presence or absence of sensitivity depends, inter alia, upon the extent of surface covered by the reactive intermediate during reaction. There is no reason to belicve that this condition is not shared by all catalytic reactions and that surface reactions may be responsive or not to the structure of the surface, depending upon kinetic conditions controlling the composition of the surface under steady state conditions, or, in other words, upon the extent of reaction conversion. Thus, the concept of reaction sensitivity should not be viewed as a set of static requirements between adsorbate molecules or molecular fragments and atomic surface sites but rather as a dynamic relationship which is a function of the extent of surface covered by the adsorbate molecules. This coverage, in turn, depends upon the position of the reaction steady state, and the reaction conversion. 'Two consequences follows from this view; namely, that (a) a reaction may be observed as structure sensitive or insensitive depending upon the extent of conversion, and (b) structure sensitive reactions may become, as a limiting case, structure insensitive at full surface coverage.

Stable bimetallic supported catalysts may be prepared with different surface activity from similar overall compositions. Preparative conditions may influence subtle distribution patterns of the two metals in the top surface layer and in the subsurface. Whether this possibility implies 
a kinetic role of the few atomic layers underneath the topmost is unclear. However, instances of interplay between surface catalytic activity and compositional variations in the subsurface resulting from the catalytic reaction are well known. Related to this latter possibility is the definition of the catalytic activity per surface $\mathrm{Pt}$ atom. Indeed, in this study a reaction rate constant (per surface Pt atom) on Pt-Au higher than on $\mathrm{Pt}$ has been observed. This realization brings forth the close correlation between the geometrical arrangements of the atoms, the morphology of the juxtaposition of the two metal aggregates, the composition of the particle surface and the electronic interactions between the two atomic species.

Effects deriving from particle morphology have already been described for unsupported bimetallic preparations (25), and this study has shown that they are also present in supported bimetallic preparations.

\section{ACKNOWLEDGMENTS}

We wish to express our thanks to T. Fukushima for the chemisorption measurements, to $F$. Garbassi for the ESCA spectra, to I. W. Bassi for the WAXS measurements, to J. D. Jones for the neutron activation analysis. One of us (S.G.) is grateful to Montedison for financial support. We acknowledge with thanks the financial support of the Dreyfus Foundation and the National Science Foundation Grant No. ENG-7514193.

\section{REFERENCES}

1. Parravano, G., J. Catal. 16, 1 (1970); S. Galvagno and G. Parravano, J. Catal. 55, 178 (1978).

2. Norton, P. R., Tepping, R. L., and Goodele, J. W., J. Vac. Sci. Technol. 14, No. 1, 446 (1977).

3. de Jongste, H. C., Kuijers, F. J., and Ponec, V., in "Preparation of Catalysts," B. Delmon,
I. A. Jacobs, and G. Poncelet (Lds.), p. 207. Elsevier, Amsterdam, 1975.

4. O'Cinneide, A., and Gault, F. (A., J. Catal. 37, 311 (1975).

5. Van Schaik, J. R. H., Dessing, R. P., and Ponec, V., J. Catal. 38, 273 (1975).

6. Biloen, P., Dautzenberg, F. M., and Sachtler, W. M. H., J. Catal. 50, 77 (1977).

7. Schwarz, J. A., Polizzotti, R. S., and Burton, J. J., J. Vac. Sci. Technol. 14, No. 1, 457 (1977).

8. Puddu, S., and Ponec, S., Rec. Trav. Chim. 95, 255 (1976).

9. Stephan, J. J., and Ponec, V., J. Catal. 42, 1 (1976).

10. Stephan, J. J., Ponec, V., and Sachtler, W. M. H., Surface Sci. 47, 403 (1975).

11. Kuijers, F. J., Dessing, R. P., and Sachtler, W. M. H., J. Catal. 33, 316 (1974).

12. Bouwman, R., and Sachtler, W. M. H., $J$. Calal. 19, 127 (1970).

13. Hagen, D. I., and Somorjai, G. A., J. Catal. 41, 466 (1976).

14. Dessing, R. P., and Ponec, V., J. Catal. 44, 494 (1976).

15. Hansen, Max, in "Constitution of Binary Alloys." McGraw-Hill, New York, 1958.

16. Fukushima, 'T., Galvagno, S., and Parravano, G., J. Catal. (1979) in press.

17. Lipson, H., and Steeple, H., "Interpretation of X-ray Powder Diffraction Patterns." St. Martin's Press, New York, 1970.

18. Theriault, G. A., Barry, T. L., Thomas, M. J. B., Anal. Chem. 47, 1492 (1975).

19. Bassi, I. W., Lytle, F. W., and Parravano, G., J. Catal 42, 139 (1976).

20. Riggs, W. M., and Parker, M. J., in "Methods of Surface Analysis," A. W. Czonderna (Ed.).

21. Avdeenko, M. A., Boreskov, G. K., and Slin'ko, M. G., in "Problems of Kinetics and Catalysis," S. Z. Roginskii (Ed.), Vol. 9, p. 61. USSR Acad. Sei. Press, Moscow, 1957.

22. Ross, P. N., and Stonehart, Paul, J. Catal. 35, 391 (1972).

29. Sinfelt, .J. H., J. Catal. 29, 308 (1973).

24. Burton, J. J., and Garten, R. L., in "Advanced Materials in Catalysis," J. J. Burton and R. L. Garten (Eds.), Academic Press, New York, 1977.

25. Schwarz, J. A., Polizzotti, R. S., and Burton, J. J., Surface Sci. 67, 429 (1977). 